\title{
Las leyes flavias, el ferrocarril, el periódico y los panes de Loring ${ }^{1}$
}

\author{
Deborah GonzÁLEZ JURADO \\ Universidad de Málaga \\ degoju@uma.es
}

Recibido: 13 de febrero de 2015

Aceptado: 29 de abril de 2015

\begin{abstract}
Resumen
Abundan las investigaciones en la formación, apogeo y fracaso del entramado financiero e industrial emprendido por el triángulo Loring-Heredia-Larios, familias burguesas que introdujeron la revolución industrial en el sur de Andalucía. Por el contrario, son casi inexistentes estudios desde la perspectiva de la mentalidad que sostuvo su modelo empresarial, social y ético en las décadas álgidas de su actuación (1850-1860). En este artículo proponemos algunas hipótesis sobre las estructuras ideológicas del grupo burgués, y señalamos algunas claves, pistas e indicios para una futura reconstrucción de este tipo, ya que hasta el momento no se ha incardinado aquella temprana y fallida revolución industrial malagueña en las corrientes de pensamiento de la época.
\end{abstract}

Palabras clave: Málaga; siglo XIX; El Correo de Andalucía; El Avisador Malagueño; leyes flavias; ferrocarril; periódicos; panes; Loring; Heredia; Larios; saint-simonismo; masonería; evergetismo; caridad.

\section{Flavian laws, the railway, the newspaper and Loring's breads}

\begin{abstract}
It is abound the research on the formation, rise and failure of the financial and industrial network undertaken by the Loring-Heredia-Larios triangle, bourgeois families who introduced the Industrial Revolution in the south of Andalusia. On the contrary, there are almost nonexistent studies from the perspective of the mentality that sustained their business, social and ethical model in the algid decades of their action (1850-1860). In this paper we propose some hypotheses about the ideological structures of bourgeois group and point out some keys, clues and signs for a future reconstruction of this kind, which so far has not been incardinated that early and failed malaguenan industrial revolution in streams thinking of that time.
\end{abstract}

Key words: Malaga; nineteenth century; El Correo de Andalucí; El Avisador Malagueño; the flavian laws; the railway; newspaper; breads; Loring; Heredia; Larios; saint-simonism; freemasonry; evergetism; charity.

Referencia normalizada

González Jurado, D. (2015). Las leyes flavias, el ferrocarril, el periódico y los panes de Loring. Historia y Comunicación Social, Vol 20, número 1, páginas: 259-286.

Sumario: 1. Introducción. 2. Las familias. 3. Los mundos antiguo y moderno en la Málaga del siglo XIX. 3.1. Ecos del protestantismo y de los nuevos tiempos en Málaga. 3.2. La construcción de la historia local. 3.3. La historia local en el siglo XIX. 3.4. Loring, Berlanga y los bronces imperiales. 4. El Correo de Andalucía. Incógnitas sobre su fundación. 5. Competencia entre El Correo de Andalucía y El Avisa- 
dor Malagueño. 6. La llegada al poder de Loring en la Junta de Comercio “por aclamación”. 7. Posibles relaciones del lobby malagueño con el saint-simonismo y la masonería. 8. El ferrocarril como gran obra de servicio cívico a la comunidad en El Correo de Andalucía. 9. Los 4.000 panes de Loring ¿Caridad o re-creación laica del antiguo evergetismo? 10. Conclusiones. 11. Referencias bibliográficas.

\section{Introducción}

En la década de 1970, Jordi Nadal abrió una línea de investigación inédita, indagando en el fracaso de una temprana revolución industrial en Málaga puesta en marcha desde las primeras décadas del siglo XIX, previamente a la que tuvo lugar en el norte de España. La desintegración del entramado industrial andaluz y la consolidación del septentrional, marcaría la diferencia y el atraso económico definitivo respecto a las regiones meridionales, quedando reducido su papel a la exportación de materias primas y al turismo en el siglo XX (Nadal, 1975).

El pasado es siempre un país extraño, pero tendemos a extrapolar nuestras concepciones presentes en él (Lowenthal, 1998: 29). Las ideologías y las mentalidades son, por tanto difíciles de aprehender cuando nos aproximamos a una época por la complejidad de sus propios mecanismos y estructuras en diferentes ritmos, engranajes y reorganizaciones constantes de la memoria y las creencias (Vovelle, 1985). Otro inconveniente que se añade al tema del que tratamos es la falta de fuentes documentales que por diversas circunstancias han sufrido innumerables desapariciones en la ciudad de Málaga. Algunas de estas desapariciones han sido producto de una negligencia contemporánea al tiempo en el que escribimos estas líneas, y otras, sospechamos, fueron perpetradas con el ánimo y la clara intencionalidad de eliminar registros comprometedores en el tiempo más o menos coetáneo al período que tratamos de estudiar.

Mediante el enmarque en las corrientes ideológicas del período en el que vivieron, la revisión de una parte de las investigaciones sobre el lobby formado por estas familias y el examen de algunas fuentes documentales y hemerográficas, podemos aventurar algunas hipótesis de aproximación al conglomerado de las estructuras subjetivas que conformaron su actividad mental y espiritual. Nos referimos a ideas sobre su papel en la sociedad y la historia bajo los enunciados de "progreso" y "bien común", a la transmutación de la "caridad cristiana" tradicional del Mediterráneo católico en una visión laicista de "responsabilidad social" bajo la guía de la apropiación y re-creación de la cultura clásica grecorromana como elemento de prestigio, a la posibilidad de que sus eclecticismos religioso y de procedencias hicieran posible la recepción del pensamiento saint-simoniano y a ciertas afinidades con la filantropía masónica. 


\section{Las familias}

Las familias de los Loring-Heredia y los Larios, estaban vinculadas entre sí mediante negocios, conociéndoselas por el triángulo Loring-Heredia-Larios, el cuál llegó a formar parte de la élite política nacional en su época ${ }^{2}$

Las familias Larios y Heredia eran oriundas de la comarca de Cameros en la Rioja, desde donde se produjo una migración norte-sur al final o justo después de la Guerra de Independencia contra la Francia napoleónica. Pablo Larios, viudo de dos matrimonios, llegaría a la ciudad desde la comarca riojana de Cameros con sus hijos, y al morir sus vástagos se dividieron -dos quedaron y dos partieron hacia Gibraltar-. De los que se afincaran en Gibraltar regresaría Martín Larios y Herreros para sustituir en los negocios a un hermano que había fallecido en Málaga, casándose con su sobrina para salvaguardar el patrimonio familiar. Más tarde obtendría uno de los títulos nobiliarios de nueva creación otorgados por Isabel II a la burguesía, Primer Marqués de Larios. Esta familia se había dedicado principalmente a la industria azucarera, textil e inmobiliaria. También de Cameros, un jovencísimo Manuel Agustín Heredia Martínez, arribó a Málaga para trabajar y pronto se dedicó al comercio, fundando con sus ganancias los primeros altos hornos de iniciativa privada de España, "La Concepción" en Marbella (1826), y más tarde "La Constancia", en Málaga capital (1833). Manuel Agustín entró en el negocio del transporte marítimo, poseyó una flota mercante y contrajo matrimonio con la hija de Thomas Livermore Page, un comerciante inglés asentado en Málaga. Las dificultades de sus negocios siderúrgicos fueron una de las motivaciones fundamentales para la promoción de la construcción del ferrocarril Málaga-Córdoba. Uno de los hijos varones de Manuel Agustín, Tomás Heredia Livermore, se haría cargo de los negocios de su padre a la muerte de éste, y fue el único de los componentes del trío que no obtuvo título nobiliario.

A principios del siglo XIX, llegó otro curioso viajero a Málaga. George Loring James, norteamericano nacido en una localidad cercana a Boston, que aunque había comenzado estudios en la Universidad de Harvard, terminó por sacarse el título de capitán de barco y dedicarse al comercio entre Málaga y Massachusetts. Contrajo matrimonio con una malagueña y fue socio de Manuel Agustín Heredia, arreglando más tarde el casamiento de uno de sus hijos, Jorge, con la hija de su colega, Amalia. Este Jorge Loring Oyarzábal sería el que recibiera otro de los títulos nobiliarios de nueva creación del reinado de Isabel II, Primer Marqués de Casa Loring.

\section{Los mundos antiguo y moderno en la Málaga del siglo XIX}

\section{1. Ecos del protestantismo y de los nuevos tiempos en Málaga}

La colonia anglosajona de Málaga, de la que formaba parte el suegro de Manuel Agustín, no era demasiado numerosa y sus miembros no encontraron dificultades 
significativas para sus negocios. Algunos obstáculos iniciales fueron interpuestos por las jerarquías católicas locales que no veían con buenos ojos la influencia sobre las creencias que estos vecinos extranjeros pudieran ejercer sobre el resto de la población, aunque en 1830 esta colonia consiguió permiso para construir sus propias infraestructuras cultuales: un camposanto y una capilla (De Mateo Avilés, 1986: 21-27; Marchant Rivera, 2004). Es posible que durante mucho tiempo siguiesen funcionando, en el sustrato ideológico de unos y otros, pervivencias de los argumentos de las intensas diatribas mantenidas por los teólogos de la Reforma sobre el origen corrupto de las instituciones de la Iglesia católica y el papado, y la contaminación de los ritos del catolicismo con el paganismo y las religiones mistéricas del bajo imperio romano (Martínez Maza, 2009).

Recordemos también que Nueva Inglaterra, en la costa este de los EE.UU., región de donde procedía el primer Loring, fue foco de la Guerra de Independencia de las colonias norteamericanas contra la corona británica. El debate sobre el modelo político a elegir para la nueva nación propició una revisión de las obras sobre formas de gobierno y derecho natural de los clásicos grecorromanos y los pensadores ilustrados (Martínez Maza, 2010; Ugarte Vial, 2010). Es seguro que el capitán Loring y su hijo Jorge -quien cursó en Harvard su título de Ingeniero de Caminos, Canales y Puertos-, hubieran estado al tanto de aquellos debates. Además, durante los años en que Loring hijo estudió en Harvard estuvieron en activo los llamados historiadores románticos norteamericanos de la Costa Este, quienes dedicaron buena parte de sus obras a estudiar el pasado hispánico desde una perspectiva crítica $^{3}$.

Antes de que el proceso constituyente americano se cerrase, estalló la revolución francesa, precipitando el viejo modelo del Antiguo Régimen a una especie de vértigo en toda Europa. En menos de diez años, los valores de los revolucionarios de igualdad, libertad y fraternidad, habían derivado en valores imperiales de nuevo cuño, con pretensiones de unificación de las distintas naciones-Estado surgentes en Europa bajo la bandera de un nuevo imperio francés. La atónita Europa pronto devengó en rechazo su sorpresa, lo que se reflejó vivamente en reflexiones de todo tipo (Wulff Alonso, 2003: 90).

\subsection{La construcción de la historia local}

En España a finales del siglo XVIII habían ido abriéndose camino las perspectivas críticas de la Ilustración europea, desde Voltaire a Kant. Carlos III, patrocinador de las excavaciones de Pompeya y Herculano en Italia, creó las Sociedades de Amigos del País, las nuevas Academias y reorganizó otras como la de la Historia de Madrid (Wulff Alonso, 2005: 46 y ss.). Era necesaria una construcción de identidad y patriotismo que explicase la derrota imperial sin afectar en exceso a la ortodoxia católica, integrase el pasado glorioso y ofreciese soluciones al atraso relativo. Se inició una revalorización de lo clásico, dándose ahora importancia inusual a la salvación y conservación de los restos arqueológicos y a la publicación rigurosa de inscripciones. La Antigüedad y el Neoclasicismo se conjugaron con tratados agrícolas e iniciativas fabriles, en un esfuerzo por salir de la decadencia ${ }^{4}$. 
El malagueño Marqués de Valdeflores había publicado en 1759 -mismo año de la llegada al trono de Carlos III-, sus Anales de la Nación Española. Esta obra fue la primera que adaptó a la cronología española la distinción de Newton de tiempo conocido, fabuloso e histórico. Pero hasta finales de aquel siglo, aún persistieron elementos de la anterior historiografía "alucinada" y confeccionada sobre fuentes fantásticas, identificándose los pueblos prerromanos con los habitantes de los reinos contemporáneos, buscando forzadas etimológicas de lugares con nombres recogidos en las fuentes clásicas, estructurando cronologías imposibles entre Noé, Tubal, griegos y troyanos, y exaltando la inocencia prístina esencial de los habitantes originarios frente a fenicios, cartagineses y romanos. Las historias locales eran obras compuestas para ensalzar las ciudades y sus méritos genealógicos. En Málaga las primeras publicadas durante la Edad Moderna habían sido escritas por jesuitas, inquisidores y otros clérigos, dándose gran mérito a los patrones de Málaga San Ciriaco y Santa Paula -mártires hispano-romanos creados por la memoria imaginada tras la conquista de la ciudad por los Reyes Católicos-. Medina Conde fue el primer historiador local que incorporó en sus Conversaciones Históricas Malagueñas (1789-1793) varias de las cláusulas ilustradas que propugnaban a finales de aquel siglo las historias nacionales de los hermanos Mohedano o de Masdeu ${ }^{5}$.

\subsection{La historia local en el siglo XIX}

El siglo siguiente fue el del triunfo de las más grandes revoluciones de la historia: la industrial y la democrática. Las búsquedas de las claves de convivencia e identidad se centraron en los nacionalismos y los Estados, intentando controlar las opciones peligrosas como el movimiento obrero. Los ateneos y liceos surgieron sobre la base del nuevo laicismo de la sociedad civil y la construcción de una opinión pública burguesa, legitimados en las ideas de conocimiento y ciencia. Aunque durante la primera parte de aquel siglo se tendió a exaltar el papel de visigodos y concilios y a identificar Roma con las pretensiones clasicistas y unificadoras de Napoleón, en la segunda mitad asistimos a otra revalorización del antiguo Imperio romano. La nueva identidad nacionalista de las élites se verá reflejada en la nueva Historia de España de Modesto Lafuente (1850-1867) .

La Historia de Málaga escrita por Ildefonso Marzo (1839) -la primera no redactada por clérigos- salió publicada en las columnas del periódico local El Guadalhorce y daba paso a los nuevos perfiles de historiadores locales: periodistas y abogados. Pero esta historia continuó en la línea de la historiografía "alucinada", atribuyendo a los íberos un monoteísmo primitivo, incluyendo referencias a Tarsis y Salomón, datando la fundación de Málaga a partir del año de la creación del mundo y subrayando la sed de oro de los pueblos conquistadores. También incluía las obligadas referencias al martirio de San Ciriaco y Santa Paula y la dulcificación de los sanguinarios godos después de su conversión al cristianismo (Pérez López, 2005: 75-79). 


\subsection{Loring, Berlanga y los bronces imperiales}

En la vigencia de este viejo modo interpretativo de la historiografía local, aparecen nuestras familias burguesas a tomar parte en un descubrimiento que dio un giro a lo anterior. En el primer ejemplar conservado en el Archivo Municipal de El Correo de Andalucía, el $\mathrm{n}^{\circ} 2$, de 1 de noviembre de 1851, salió publicada una noticia que, podríamos decir, supuso el debut de un "pequeño Renacimiento" en la ciudad en plena Revolución Industrial ${ }^{7}$. Al final de la última columna de la primera página comienza un artículo de dos columnas sobre el descubrimiento fortuito durante la semana anterior de dos grandes tablas de bronce con inscripciones, en una extracción de barro realizada por unos tejeros en Calle de Olletas -aún existente con el mismo nombre en la actualidad-. Estos bronces resultaron ser la Lex Flavia Malacitana y la Lex Flavia Salpensiana (Rodríguez Oliva, 2001). La noticia nos informa de que el señor don Jorge Loring había adquirido rápidamente aquellas tablas, poniéndolas a disposición del erudito que escribía para su descifrado.

La noticia no está firmada, pero sabemos que fue escrita por Ildefonso Marzo, nuestro historiador por capítulos de El Guadalhorce, quien era el académico correspondiente para esa instancia en aquel momento. La primera reproducción de aquellos bronces y la primera solicitud a la Real Academia de la Historia para su estudio se debieron a él. Al poco tiempo llegó a Málaga el joven abogado y epigrafista Rodríguez de Berlanga estaba en realidad mucho mejor preparado que Marzo, ya que era un hombre plenamente formado en la sistémica positivista de la nueva historia y su trabajo crítico (o hipercrítico) como historiador, contribuyó al desbroce de la historia de Málaga al cobijo de la ciencia. Al poco de entrar en contacto con Jorge Loring a raíz del hallazgo de las tablas, Rodríguez de Berlanga pasó a dedicarse a su estudio y llegaría a ser esposo de una hermana del industrial, quien ya había contraído nupcias con Amalia Heredia en 1850. Así que la fama creciente del acomodado erudito, hizo que este pequeño detalle de la primacía del descubrimiento fuese cayendo en el olvido (Wulff Alonso, 2002: 114 y ss.). Y el título de académico correspondiente de la Real Academia de la Historia recayó en Berlanga en $1857^{8}$, tras el fallecimiento de Marzo en 1856.

La transcurrida entre 1850 y 1860 fue una década de plenitud para los Loring y su familia extensa. Así pues, las líneas genealógicas Loring y Heredia se afianzaron mediante unión matrimonial en 1850. En 1851 se fundó El Correo de Andalucía y se descubrieron las tablas de bronce. En 1852 Tomás Heredia alcanzó el grado de Cónsul en el Tribunal de Comercio. Rodríguez de Berlanga, recibió el título de Caballero de la Real Orden de Isabel la Católica en los años inmediatamente posteriores a su descubrimiento arqueológico y sería nombrado miembro correspondiente de a Real Academia de la Historia en 1857. Loring obtuvo el Marquesado en 1856, con el emblema "faire sans dire", como gratificación a su contribución activa en la epidemia de cólera de Málaga por su donación de medicinas gratuitas entre el pueblo entre 1854 y 1855, y esta acción fue considerada por el Ayuntamiento "uno de los mayores ejemplos de la caridad cristiana" . La familia, junto con los Heredia 
y los Larios, fundó el Banco de Málaga en 1856 (Morales Muñoz, 1983: 53 y ss.) y continuó adelante con el ambicioso proyecto de la construcción del ferrocarril Málaga-Córdoba, cuya concesión fue otorgada a Loring en 1860, aunque la línea férrea no se abriría hasta 1866. Durante aquel decenio continuó la afición de la familia por el mundo antiguo y fueron célebres las jornadas de discusión política, histórica y literaria en "La Concepción” (Rodríguez Oliva, 2006).

\section{El Correo de Andalucía. Incógnitas sobre su fundación}

Entre el Archivo Municipal de Málaga y el Archivo Díaz de Escovar de la misma capital, se conserva parte importante de la colección del periódico El Correo de Andalucía ${ }^{10}$. Aunque cambió de subtítulo varias veces, salió con el de Diario político, de comercio, artes, industria, agricultura y estadística. Este diario liberal de amplio contenido se publicó entre finales de 1851 y los años noventa del siglo XIX, aunque no tenemos constancia exacta de la fecha en que dejó de imprimirse, y llegó a ser uno de los más relevantes diarios en la historia del periodismo malagueño.

Es tenido por cierto entre los historiadores locales del presente que El Correo de Andalucía fue fundado por Jorge Loring Oyarzábal o, al menos, que el burgués aportó una parte importante de su capital inicial, pero nosotros no hemos encontrado ninguna referencia contrastada sobre la que poder basar dicha afirmación, ni en los textos del mismo periódico, ni en fuentes, ni en la bibliografía disponible ${ }^{11}$. Sobre los propietarios y fundadores del periódico, tenemos información en el catálogo de Ossorio y Bernard, atribuyendo dicha cabecera a los hermanos Narciso y Ramón Franquelo y Martínez. De entre ellos, el primero fundaría otro periódico llamado El Mediodía en 1875, del que a su vez sería director uno de sus hijos, Carlos Franquelo y Romero. Los tres Franquelo trabajaron y escribieron en El Correo... (Ossorio y Bernard, 2004: 144 ), de cuya aparición tenemos constancia exacta hasta el 9 de abril de 1890, fecha en la que termina la colección más larga, la del Archivo Díaz de Escovar. Este periódico tenía imprenta propia, figurando como su titular uno de los hermanos, Ramón. La firma de imprenta aparece en todos los ejemplares: "Círculo Literario, Calle Casapalma, 7"'12.

\section{Competencia entre El Correo de Andalucía y El Avisador Malagueño}

El trabajo completo de Berlanga sobre los bronces con las leyes Flavias hallados en Málaga se publicó en 1853 y fue titulado Estudios sobre los dos bronces encontrados en Málaga a fines de octubre de 1851 por el doctor Manuel Rodríguez de Berlanga, abogado del ilustre Colegio de esta ciudad (Rodríguez de Berlanga, 1853). Esta publicación conmocionó al mundo académico del momento en toda Europa, siendo alabada por diversos estudiosos del derecho antiguo y la arqueología. El 
celebérrimo Mommsen, quien se hallaba en ese momento recopilando inscripciones para su Corpus Inscriptionum Latinarum (CIL), envió a uno de sus corresponsales a Málaga a ponerse en contacto con Berlanga y verificar las tablas in situ ${ }^{13}$.

Llama la atención el hecho de que, aunque la primicia del descubrimiento de las tablas de bronce romanas imperiales saliese en el segundo número de El Correo..., Rodríguez de Berlanga publicase el resultado final de su estudio en 1853, con la transcripción de los textos por fascículos en la Revista semanal pintoresca del Avisador malagueño, y una tirada aparte con el trabajo completo el mismo año, también en la Imprenta de El Avisador..., y no en la imprenta de El Correo...

El Avisador Malagueño, fundado en 1843 y desaparecido en 1893, fue el otro gran periódico generalista de la ciudad durante la segunda mitad del siglo XIX ${ }^{14}$, con el cuál, El Correo de Andalucía hubo de entrar en competencia directa desde su creación. El Avisador ... se confeccionaba en la imprenta de José Martínez de Aguilar, y cumplía con todas las características de la prensa europea más vanguardista de su época, recordando a las revistas inglesas especializadas en anuncios: por su título, por el tratamiento publicitario de todas las informaciones que ofrece, y por la inclusión de signos para la lectura, como pequeñas manos con el índice extendido como resalte ${ }^{15}$.

La organización del comercio en instituciones municipales había comenzado a finales siglo XVIII, las cuales se convirtieron en auténticos ejes de la vida económica y social de las ciudades ${ }^{16}$. Sobre estas Actas de la Junta de Comercio de Málaga se han realizado diversos estudios que han obviado el análisis de las informaciones sobre prensa, imprentas o empresas informativas de la época que sí contienen los originales manuscritos ${ }^{17}$. La competencia por el mercado que debieron mantener estas dos cabeceras malagueñas desde mediados del siglo XIX, podemos seguirla también en los legajos manuscritos de las Actas de la Junta de Comercio (1839-1854), conservadas en la Cámara de Comercio de Málaga ${ }^{18}$. En las Actas de la Junta de Comercio de 18 de marzo de 1845, y 4 y 27 de enero de 1849, se ordenaba expresamente la publicación de varias decisiones de aquella cámara en El Avisador... en detrimento de otro periódico liberal generalista más antiguo llamado El Despertador Malagueño ${ }^{19}$.

Acerca de la cuestión de la publicación del insigne trabajo de Berlanga sobre las leyes flavias, si diéramos por hecho que El Correo... fuese fundado por Loring -o al menos que mantuviese estrechas relaciones con la planificación empresarial de las familias industriales-, podríamos barajar varias hipótesis. Podría haberse dado el caso de dificultades técnicas de la impresión o el ejercicio de una competencia laxa entre las dos cabeceras, o que surgiesen desavenencias coyunturales entre ambos futuros cuñados. Pero teniendo en cuenta datos de estudios actuales que indican una suspensión temporal que sufrió El Correo de Andalucía pocos meses después del inicio de su actividad (Checa Godoy, 2011: 113-114), tal vez lo más razonable sería pensar que Loring y Berlanga no hubieran querido retrasar la preparación del trabajo a causa de posibles eventualidades contra el periódico provocadas por detractores del lobby con influencia en los órganos centrales del Gobierno de Madrid. 


\section{La llegada al poder de Loring en la Junta de Comercio "por aclamación"}

En las Actas de esta Junta de Comercio vislumbramos indicios de una posible maniobra política del lobby Loring-Heredia-Larios para apropiarse del proyecto del ferrocarril de María Cristina, que había sido iniciado por una empresa pública de la municipalidad ${ }^{20}$. Ciertamente tal vez Loring fundase El Correo... con el objetivo de convertirlo en una herramienta de influencia sobre la opinión pública y así redondear el ambicioso proyecto de negocios del lobby a nivel regional, diversificado e integrado a un tiempo.

En una sesión de la Junta de 6 de febrero de 1851, se leyó una Real Orden en la que se nombraba Cónsul del Tribunal de Comercio de la ciudad a Tomás Heredia, y en otra sesión de 1 de enero de 1852, se relata cómo Jorge Loring toma posesión del cargo de vicepresidente de tal organismo "por aclamación", con la omisión del secretario del acostumbrado juramento del cargo en la redacción del acta, comentándose en cambio que el gobernador de la provincia autorizó tal toma de posesión mediante oficio del día 22 de diciembre pasado. A partir de aquel momento el siguiente apunte sobre una inserción de decisiones en prensa local aparece en la sesión de 7 de abril de aquel mismo año, ordenándose llevarse a cabo en El Correo de Andalucía y no en El Avisador ..., como era acostumbrado hasta la fecha. En las Actas a partir de 1854 encontramos más menciones acerca de inserciones en los periódicos locales pero ya no se especifica en cuáles, por lo que entendemos que El Correo de Andalucía habría desbancado a El Avisador ... como órgano de comunicación de la Junta.

Manuel Agustín Heredia, el padre de Amalia, había sido Prior del Consulado de Comercio en 1824 y Martín Larios Herrero Presidente de la Junta en 1835 (Morales Muñoz, 1999: 431-449). Pero en las Actas manuscritas de 1 de enero de 1843, Manuel Agustín ya figura solamente como vocal y encargado de las secciones de Comercio y Empresas e integrante de la Comisión del Ferrocarril de $\mathrm{M}^{\mathrm{a}}$ Cristina en la de 19 de enero del mismo año; mientras que no figura ningún Larios o Loring con cargos en esos años. En el Acta de 9 de marzo de 1849, su hijo Tomás Heredia se inscribe también solo como vocal, pasando directamente, al cabo de dos años, a ser Cónsul del Tribunal de Comercio. A partir de este hecho Jorge Loring, recientemente convertido en cuñado de Tomás, se hizo a su vez con el cargo de vicepresidente -resaltamos"por aclamación", justo dos meses después de la fundación de El Correo de Andalucía y de la aparición de las tablas de bronce. De nuevo, la forma de ascensión al poder municipal de Loring nos puede sugerir una re-creación de los usos de la Antigüedad, sin perder de vista que esta especial toma de posesión del cargo en la época contemporánea significaba trascender los modos legales y reglamentarios al uso.

A partir de la lectura de estos documentos podríamos aventurar, aunque con los reparos de enunciar una hipótesis puramente especulativa, que a partir de principios de la década de 1850, el lobby Loring-Heredia-Larios, efectuó un "golpe de mano" para hacerse con el gobierno de la Junta de Comercio de Málaga, maniobra en la que pudo tener que ver la creación del nuevo diario y, tal vez, la intención de hacerse con 
el proyecto de la construcción del ferrocarril Málaga-Córdoba, que en manos de las instituciones oficiales de la ciudad se había visto largamente demorado.

\section{Posibles relaciones del lobby malagueño con el saint-simonismo y la masonería}

La planificación empresarial del lobby malagueño, aunque a pequeña escala, muestra acusadas semejanzas con los de otra acaudalada familia francesa rival de los Rothschild, los Péreire. La diversificación de las empresas de los hermanos Péreire y el riesgo de sus inversiones de capital son bien conocidos, al igual que el estrangulamiento final de sus negocios (Fargette, 2001); resultado paralelo al que desembocaron los de los Loring-Heredia-Larios. El proyecto de construcción y puesta en funcionamiento de la vía férrea Málaga-Córdoba fue la piedra angular en el intento de consolidación de una estructura de negocios de ámbito regional dilatadamente diversificada, ya que la estrategia del lobby malagueño trataba de abarcar todos los sectores productivos de negocios y finanzas, desde las flotas navieras comerciales a vapor, hasta la producción y transformación de cultivos innovadores, pasando por la siderurgia, la textil, la inmobiliaria, la imprenta, etc. (Lacomba, 1974: 53 y ss.; Tedde de Lorca, 1978: 367 y ss).

Las pequeñas diferencias entre la diversificación sectorial de los Péreire y la de los Loring-Heredia-Larios puede ser debida, simplemente a que el sustrato geográfico y cultural en el que se desarrollaron ambas era también diferente. Aunque las inversiones de Péreire en imprentas, prensa y publicidad, se desarrollaron mucho más intensivamente que las de los Loring-Heredia-Larios, si aceptáramos que El Correo de Andalucía contó con la capitalización del trío, este periódico habría significado un punto de partida hacia los sectores de la prensa y la publicidad. En cuanto a la publicidad, una actuación más amplia como la de los Péreire en Francia ${ }^{21}$ hubiera resultado absolutamente irrealizable en Málaga en aquel momento, pero la visión de los Loring-Heredia-Larios no dejó de ser vanguardista en esta actividad, y a la inauguración del ferrocarril Córdoba-Málaga (1866), ya existía un concesionario en exclusiva que ofrecía a los anunciantes espacios para sus carteles en diversos puntos de la pequeña red ferroviaria en la moderna librería Francisco Moya de la capital (González Jurado, 2014: 76-78) . Por tanto, aunque no tenemos constancia de inversiones directas en los negocios de la información, sí hemos encontrado, al menos, que el grupo tomó parte o estuvo muy próximo a una red de iniciativas de la información en Andalucía, en asociación con empresas especializadas en éstos.

Los hermanos Péreire fueron saint-simonianos convencidos, y se nutrieron directamente de las doctrinas originales de Saint-Simon, sobre la base de un socialismo pre-marxista que no tomaba en cuenta la lucha de clases entre el capital y el trabajo. Los Péreire se codearon con varios de sus discípulos más relevantes, como Pierre Leroux -masón y redactor principal en Le Globe, periódico en el que invirtieron los Péreire-, Prosper Enfantin -promotor de ferrocarriles y de la transformación de las 
doctrinas de Saint-Simon en nueva religión-, y a Ferdinand Lesseps -ingeniero de los grandes canales (Suez 1869 y Panamá 1914, hasta 1889)-. Según las doctrinas de Saint-Simon, la sociedad debería organizarse por los industriales para promover el bienestar de la clase más numerosa y más pobre, y la contribución de Saint-Simon al pensamiento socialista de los primeros tiempos fue la concepción de una planificación social de la economía (Cole, G. D. H., 1957: 13 y ss.). Sobre la recepción del saint-simonismo en España, la investigación baraja las posibilidades de su llegada a España a través de Gibraltar, en las idas y venidas de los exiliados en Inglaterra y Francia tras la vuelta de Fernando VII; exiliados entre los que se dio un eclecticismo de creencias superlativo. En el norte, el saint-simonismo fue calando por medio de la acción directa a base de propaganda y publicaciones en Barcelona, como la que llevó a cabo Covert-Spring (Sánchez Hormigo, 2004). Parece ser también que Manuel Agustín Heredia había sido amigo personal de Ferdinand Lesseps desde 1839, y que el puerto de Málaga y los negocios de aquél fueron altamente beneficiados por la apertura del Canal (Daza Sánchez, 2005: 268).

El grupo de industriales malagueños se había opuesto a las aspiraciones del grupo Rothschild y sus socios, de quienes los Péreire eran sus principales competidores. El grupo Rothschild pretendía adquirir las concesiones de las líneas ferroviarias andaluzas hasta Málaga para entroncarlas con la construcción del Gran Central, un portentoso proyecto ferroviario francés que finalmente no se llevó a cabo. La adjudicación definitiva de la línea Córdoba-Málaga fue concedida a Jorge Loring, como hemos visto, frustrándose así los planes de uno de los más poderosos grupos de inversión franceses (Cuéllar Villar y Sánchez Picón, 2008: 103-109). Es muy probable que los Loring-Heredia-Larios, ejerciesen una competencia consciente contra el capital galo al crear el Banco de Málaga, pues su puesta en funcionamiento coincide con la entrada en vigor de la ley de 1856, que autorizaba la creación de sociedades financieras según el modelo francés. Aquel mismo año los grandes bancos del Hexágono no habían dudado en intervenir en la Península, instalando filiales rápidamente en España: El Crédit Mobilier Espagnol, de los Péreire; la Société Espagnole Mercantile et Industrielle, de los Rothschild; y la Compagnie Générale de Crédit en Espagne, de Prost-Guilhou (Broder, 1998) ${ }^{22}$.

Hasta la abolición de la Inquisición en las Cortes de Cádiz, la masonería no pudo organizarse en España (Ferrer Benimeli, 1980: 23-29). Los estudios sobre la masonería malagueña, pertenecientes a la línea de investigación abierta en los años ochenta del siglo XX sobre este tema en nuestro país (Ferrer Benimeli, 2010), o no ahondan en la identificación de los miembros de las logias, o comienzan y se concentran en el último tercio del siglo XIX, período de esplendor y reorganización de la masonería ${ }^{23}$. A partir de ese final del siglo XIX podemos incluso seguir la pista de la asimilación de la filantropía masónica en España a través de los preceptos que se adoptaron con el krausismo en la pedagogía (Alvarez Lázaro, 1999). Pero según el estado actual de la investigación, respecto a la década que estudiamos aquí (1850-1860 aprox.), no somos capaces más que de enhebrar indicios y plantear preguntas. 
Un masón ilustre de la época, relacionado con el desarrollo de las tendencias de la economía política y pionero en el modelo de aplicación del análisis matemático fue el malagueño Juan López de Peñalver (1764-1834), ingeniero ilustrado educado en el extranjero. Además de su destacada obra Reflexiones sobre la variación del precio del trigo (1812), mantuvo colaboraciones con diversas publicaciones periódicas, entre ellas La Gaceta de Madrid, el Mercurio de España, y otras ediciones ministeriales. En su tiempo gozó de excelente reputación entre estadistas y literatos (Perdices de Blas y Sánchez Hormigo, 2007: 101). Es probable que López de Peñalver hubiese mantenido contacto al menos con Manuel Agustín Heredia, ya que parece que participó en la confección de algún proyecto para la retención de riadas del Guadalmedina, problema que afectaba al comercio y a las actividades portuarias, y realmente a toda la ciudad (Villas Tinoco, 2002).

Algún estudio reciente basado en los archivos documentales que se han conservado en las minas de carbón de Belmez, propiedad de nuestras familias burguesas, asevera la pertenencia a la masonería de Jorge Loring y del padre de su esposa, Manuel Agustín Heredia. Parece ser que el afamado masón Leopoldo Alcántara Palacios, ingeniero al cargo del ferrocarril Puente Genil-Cabra, propiedad también de Loring, colaboró en la logia "Antorcha Pontana" de Puente Genil, en Córdoba, y que tuvo por nombre simbólico "Lesseps" por su admiración al ingeniero francés saint-simoniano. Nuestro industrial, Jorge Loring, se supone vinculado a las logias "Luz" de Málaga y "Luz de la Sierra" de Belmez, localidad esta última, donde estaban ubicadas las minas del lobby a las que se pretendía llegar con el ferrocarril. A su vez estas dos logias estarían vinculadas a "Antorcha Pontana"24. Precisamente fue también en Puente Genil, donde había aparecido fortuitamente un sarcófago hispano-romano que también adquirió Jorge Loring y pasó a formar parte de su colección arqueológica (Beltrán Fortes, García García y Rodríguez Oliva, 2006: 42-45), lo cual sigue haciendo destacar que Loring mantenía influencias y gozaba de preeminencia en las informaciones y la actualidad del momento en toda la región andaluza, sobre todo en las comarcas en las que mantenía negocios. Pero la logia "Luz", $\mathrm{n}^{\circ}$ 187, situada en calle Granada $\mathrm{n}^{\mathrm{o}} 13$, piso segundo izquierda, dependiente del Gran Oriente Español y patrocinada por el Gran Oriente Lusitano Unido, con registro en esa Secretaría con el número 7, fue fundada el 30 de junio de $1879^{25}$, siendo por tanto posterior a la década que aquí investigamos.

Efectivamente, durante el último tercio del siglo XIX, que se corresponde con el gran florecimiento de la masonería en nuestro país -ribeteado de escisiones constantes en multiplicidad de obediencias-, se sucedieron los nombramientos de personajes ilustres como Zorrilla, Sagasta, etc. ${ }^{26}$; y es posible que tal fuese el caso de Jorge Loring. Sin embargo, si Manuel Agustín Heredia perteneció a la masonería ${ }^{27}$, por la fecha de su fallecimiento en 1846, entendemos que fue masón durante el período de prohibición de esta asociación. Si fuere el caso de que Jorge Loring también perteneciese a la masonería previamente a su legalización, puede ser un indicio de ello la única mención que hemos hallado de que posiblemente tuvo problemas con la Iglesia católica en 1865, ya que sabemos que el 3 de febrero de aquel año otorgó 
"poder especial al procurador del juzgado de Marbella Antonio Gómez, para que lo defienda en todos los pleitos, causas y negocios civiles, criminales y eclesiásticos", según los documentos del Archivo Histórico Provincial de Málaga, legajo 4.640, fols. 177 y $178^{28}$.

\section{El ferrocarril como gran obra de servicio cívico a la comunidad en El Correo de Andalucía}

Volvamos a El Correo de Andalucía. El número 2580, de jueves 15 de marzo de 1860, se dedicó casi por completo a la concesión del ferrocarril Málaga-Córdoba a Jorge Loring.

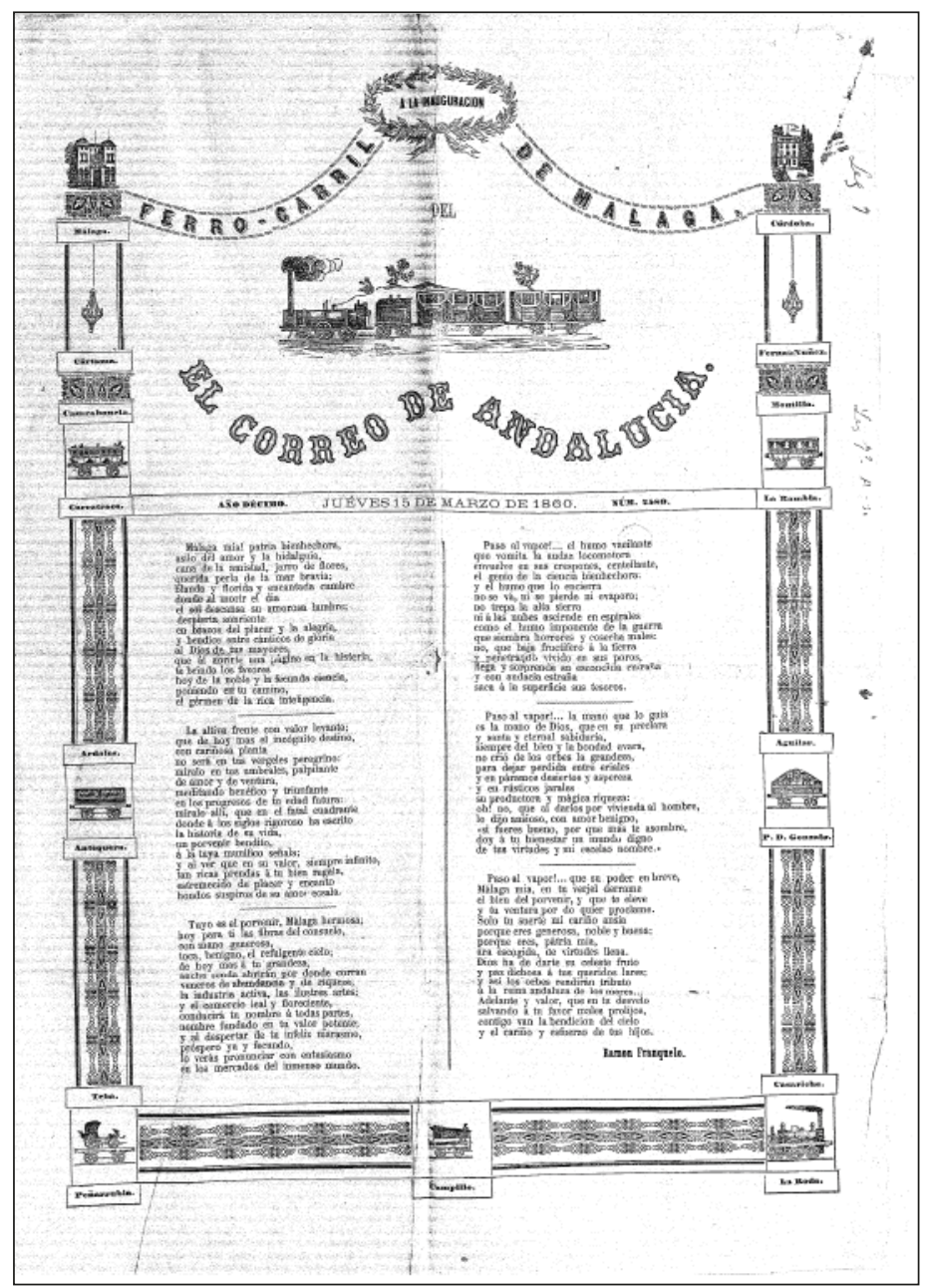




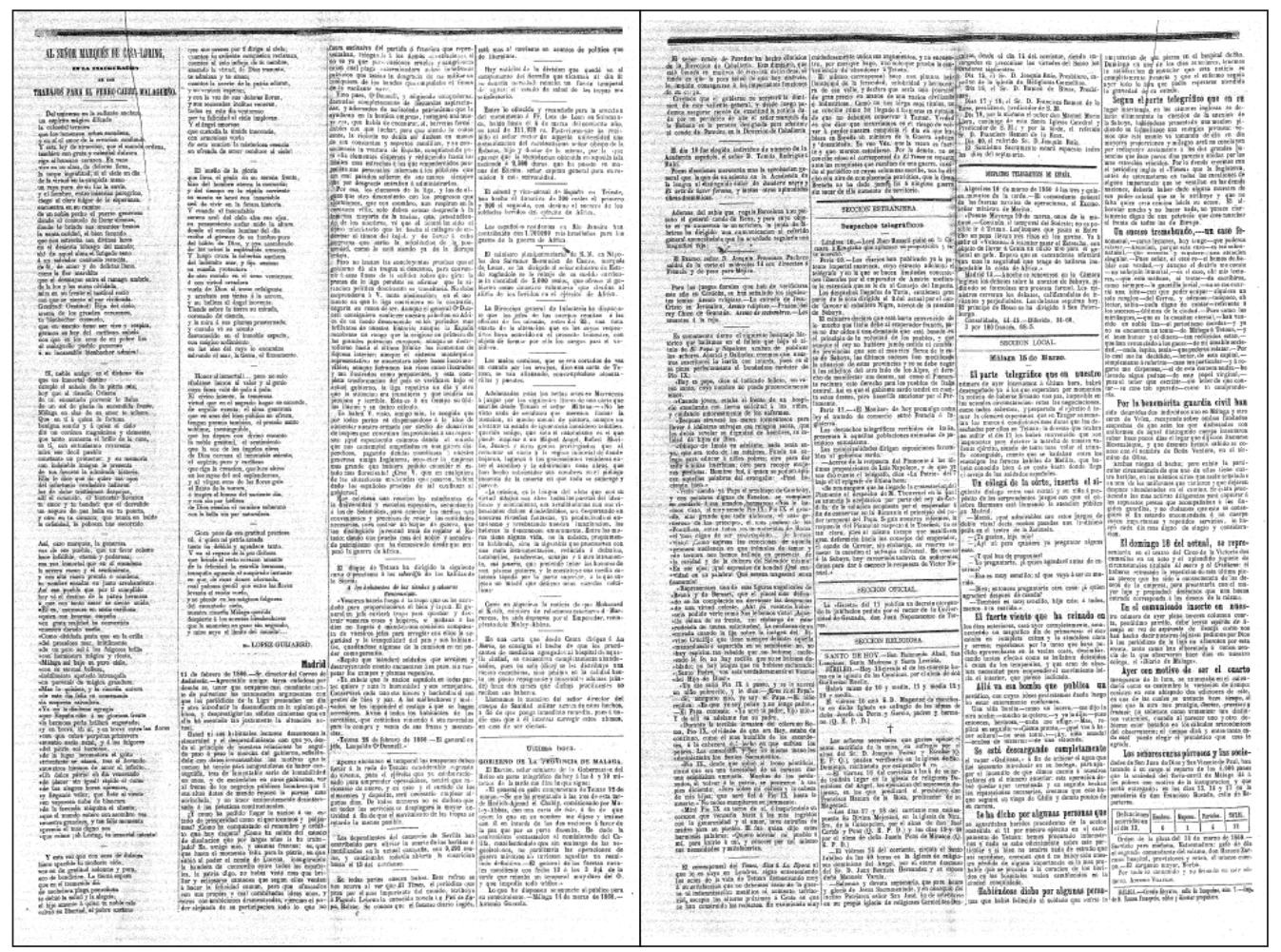

Las dos primeras planas de este número está ocupado con composiciones literarias laudatorias del promotor del ferrocarril de Málaga, la primera con referencias indirectas y tocando el tema desde una perspectiva general, firmada por Ramón Franquelo, y la segunda directamente dedicada a Jorge Loring, firmada por López Guijarro. Estas expresiones en verso pretenderían, a un tiempo, ensalzar al promotor y la gran obra pública que brindaba a la ciudad, y destaca en ellos su finalidad de dar publicidad al proyecto ferroviario en vísperas del comienzo de las obras y generar una opinión pública positiva en vísperas del comienzo de las obras.

Aquel número salió a modo de "especial" con clara intención propagandística y formato diferente al habitual, compuesto por tres páginas, con la primera plana ilustrada en sus bordes con imágenes, y una cenefa en el borde superior, con el título "Á LA INAUGURACIÓN DEL FERRO-CARRIL DE MÁLAGA" rodeada por una corona de laureles rodeando las palabras " $A$ LA INAUGURACIÓN". Lo interesante en la composición de la imagen en esta portada de El Correo... es la sustitución de elementos decorativos arquitectónicos tradicionales de pináculos, columnas y capiteles renacentistas o neoclásicos, por elementos de modernidad, como edificios contemporáneos y pequeñas ilustraciones con motivos ferroviarios. El símbolo de la corona de laureles es un elemento que nos remite al mundo antiguo. Se colocaba en la cabeza de los conquistadores, recibidores del honor del Triunfo, y había pervivido 
como elemento recurrente a través la iconografía de las edades Moderna y Contemporánea, apareciendo siempre en monumentos y escultura pública, y acompañando diversos temas mitológicos ${ }^{29}$.

También en la parte superior, enmarcada entre la frase que da título a este número especial y el nombre del periódico, se inserta el grabado de un tren con locomotora, su maquinista y un ténder con dos fogoneros y dos vagones de viajeros, atravesando un paisaje hacia la izquierda. En los bordes ilustrados se colocan espacios a modo de cartelas con los nombres de las localidades que conectaría el ferrocarril entre Málaga y Córdoba. Las pequeñas ilustraciones a ambos lados -de arriba abajo- representan dos edificios que no identificamos, pero podrían ser figuraciones idealizadas, tal vez, de los antiguos ayuntamientos de Málaga (edificio tipo austríaco con dos torres a los lados, hoy desaparecido, que estuvo situado en la actual plaza de la Constitución) y de Córdoba (en la plaza de la Corredera); no obstante, estos dibujos no reproducen una representación real en ninguno de los dos casos, y tampoco se trata de imágenes de las estaciones de ambas ciudades, las cuales aún siquiera se habían proyectado. En orden bajo las imágenes de los edificios, dos lámparas de araña de cristal con velas, dos vagones de viajeros, dos de mercancías, un coche de caballos de cuatro ruedas tipo "Milord" 30 sobre una plataforma con ruedas de carril, y otra pequeña locomotora. La cenefa se completa con adornos de entramados geométricos, vegetales y bandas. Las cartelas laterales superiores anuncian los nombres de Málaga y Córdoba, una a cada lado. El resto de las cartelas, a la izquierda: Cártama, Casarabonela, Carratraca, Ardales, Antequera, Teba y Peñarrubia. A la derecha: Fernán Núñez, Montilla, La Rambla, Aguilar, P. D. Gonzalo, Casariche y La Roda. En la banda inferior, otra cartela en el centro con el nombre de Campillo. Estas localidades se corresponden con el proyecto del trazado inicial que finalmente se desvió, y algunas de ellas quedaron fuera del recorrido, pasándose a integrar las minas de Belmez que tanto interesaban al lobby para su industria siderúrgica ${ }^{31}$.

Comparando esta primera plana de El Correo de Andalucía con el perfil longitudinal del trazado de 1906 conservado en el Archivo Ferroviario de Madrid ${ }^{32}$, de las estaciones probables referidas en esta portada, desde Córdoba a La Roda tales como Fernán-Núñez, Montilla, Aguilar y Casariche, todas fueron construidas según los planes previstos, siendo la única que no aparece en el perfil longitudinal la de P.D. Gonzalo. Sin embargo, desde La Roda a Málaga se produjeron a posteriori los cambios principales del trazado de la línea, construyéndose solamente la estación de Cártama, y descartándose Campillos y Carratraca. Antequera tampoco sería incluida en la línea inicial de Córdoba a Málaga, y habría de esperar a la construcción de la línea de Bobadilla a Granada para ser conectada a la red ferroviaria. Tampoco atravesó finalmente el ferrocarril ni Casarabonela, ni Ardales ni Teba.

Toda la primera plana está ocupada con una composición en verso firmada por el director, impresor y propietario de El Correo..., Ramón Franquelo (Ferreras, Juan Ignacio, 1979: 160) ${ }^{33}$. La composición sin título de Ramón Franquelo está dedicada a la llegada del ferrocarril a Málaga, ensalzando las virtudes de la ciudad de forma clásica pero intercalando trazos de elementos de modernidad y de apertura al futuro 
en su contenido. Consiste en versos endecasílabos de rima consonante, la mayoría de los cuales tiene once sílabas, aunque hay versos más cortos. La disposición de los versos cortos altera el ritmo regular de las sílabas, y puede significar la introducción de otro rasgo de modernidad en estas estrofas. Las seis estrofas de esta composición cuentan entre catorce y diecisiete versos cada una, en rima consonante. En la segunda mitad de la composición se hacen alusiones directas al maquinismo del ferrocarril, algo que no sería tema común de la poesía hasta ya entrado el siglo XX con la irrupción de los vanguardismos. Son expresiones llamativas generadoras de imágenes vívidas y se hacen referencias al amor de "los hijos de la ciudad", en alusión a los promotores del ferrocarril.

La segunda plana de este ejemplar de El Correo..., cuenta con cuatro columnas, de las cuales, la primera y media se llena con otra composición en siete estrofas, en endecasílabos consonantes con algunos versos más cortos, en forma de oda dedicada ya directa y explícitamente a Jorge Loring. Está firmada por el granadino Salvador López Guijarro, político liberal en la Restauración nacido en 1834, periodista y poeta parnasiano ${ }^{34}$. Estos versos de López Guijarro, llevan por título " $A L S E \tilde{N} O R$ MARQUÉS DE CASA-LORING, EN LA INAUGURACIÓN DE LOS TRABAJOS PARA EL FERRO-CARRIL MALAGUEÑO”. Todo el poema comienza haciendo mención a un "espíritu mágico" del universo, una ley de atracción o amor universal que conecta todo lo existente en el orbe, cuestión que podría estar relacionada con la visión masónica de un ente supremo arquitecto del universo. No obstante, las palabras son utilizadas en doble sentido y con connotaciones sutiles ya que, aunque se habla de "santa caridad" o "fe" o "amor", los símiles y asociaciones no son utilizados en los términos tradicionales de la poesía religiosa, sino que juegan con dobles sentidos más afines a una ética universal. Las dos primeras estrofas giran en torno a la gratitud del pueblo malagueño al bienhechor admirado, es decir, al promotor de la línea, el marqués de Lorign. En la segunda, se incluye la expresión "risueño Oriente”, que bien podría interpretarse bajo las claves de la filosofía masónica, aunque puede referirse simplemente a la posición geográfica de Málaga, en el oriente de Andalucía; otro ejemplo de doble sentido en el juego de significantes y significados que emplea el autor. La tercera estrofa hace mención indirecta al clima benigno de la ciudad de Málaga y también realiza un giro hacia el maquinismo, introduciendo la locomotora como protagonista de la composición. La cuarta estrofa vuelve a la gratitud popular hacia el benefactor, mencionando el débito de la ciudad con Loring por la "asoladora plaga ponzoñosa" que la asoló, en recuerdo de la epidemia de cólera que comentábamos en otro epígrafe, y menciona la modestia del promotor. La quinta estrofa gira alrededor de la inteligencia, el "pensamiento audaz", el "genio" del personaje, su "sed de vivir en la futura historia”. La sexta estrofa habla de "cívico interés", de "bien público", y de nuevo de "la gratitud". La última estrofa insistirá sobre este último tema. 


\section{Los 4.000 panes de Loring ¿Caridad o re-creación laica del antiguo everge- tismo?}

El mismo número de aquel 15 de marzo de 1860, en la tercera y última plana encontramos un insólito pequeño anuncio que dice:

Los señores curas párrocos y las sociedades de San Juan de Dios y San Vicente de Paul, han tomado á su cargo el reparto de los 4.000 panes que la sociedad del ferro-carril de Màlaga dá à los pobres con motivo de la inauguracion y que serán entregados en los días 15, 16 y 17 en la panadería de don Francisco Rosado, calle de Esparteros $^{35}$.

Este pequeño anuncio ha sido pasado por alto hasta la fecha por la investigación aunque se trata de un caso singular. Hasta el momento no hemos encontrado ningún otro caso de reparto de panes con motivo de inauguraciones de líneas férreas en periódicos, ni tampoco en las Actas de MZA (Ferrocarril de Madrid a Zaragoza y Alicante $^{36}$-la red ferroviaria de los Rothschild-, aunque tampoco descartamos taxativamente que pudieran aparecer.

Las posturas ante el problema del pauperismo generado en el largo período de transiciones desde la sociedad feudal a la sociedad mercantilista, y de ésta a la capitalista, estuvo jalonado de muy diversas respuestas de la beneficencia en España. Durante los siglos XVIII y XIX, el proceso de secularización, los intentos de aplicación de la nueva ciencia económica a la agenda de intervención estatal y la orientación productivista de la incipiente industrialización, habían desembocado en la inserción de pobres en trabajos públicos, y en el encierro de vagos y mendigos en hospicios y hospitales como profilaxis para eliminar los riesgos sociales. Los gremios y cofradías fueron sustituidos por la creación de montepíos, cajas de ahorros y sociedades mutuas. Las monarquías del XVIII, en su afán de centralización y racionalización administrativas, crearon sistemas de asistencia pública opuestos a la caridad religiosa tradicional, la cuál sufrió un ataque frontal con las primeras medidas desamortizadoras del XVIII. El golpe definitivo a la función asistencial de la Iglesia vino por parte del Estado liberal del XIX, adoptándose la beneficencia pública y la seguridad social. El espíritu laico sobre asistencia pública de las Cortes de Cádiz de 1812, se reverberará en las desamortizaciones de los bienes, diezmos de la iglesia y prerrogativas asistenciales a partir de mediados de los años 1830. El Real Decreto de 29 de julio de 1837, aunque extinguía todos los monasterios, conventos, colegios, congregaciones de ambos sexos y suprimía la contribución de diezmos y primicias, dejaba abierta la posibilidad de que algunas instituciones religiosas como las hermanas de la caridad de San Vicente de Paúl, se dedicaran a la hospitalidad y la enseñanza en los establecimientos civiles (López Castellano, 2004).

El análisis de este anuncio sobre el reparto de panes de la Sociedad del Ferrocarril de Málaga a Córdoba, y por ende de Loring, nos revela la posición ambigua de la iniciativa de los burgueses malagueños respecto a su función en la sociedad, ya que admite interpretaciones opuestas. Por un lado, el gesto podría incardinarse en la visión de las escuelas historiográficas establecidas por Vicens Vives y Jover Zamora, 
en el que un nuevo paternalismo burgués se superpone y sustituye al anterior paternalismo de la aristocracia del Antiguo Régimen, reforzando la ideología proselitista más reaccionaria sobre la pobreza de la Iglesia católica española ${ }^{37}$. Pero nos parece más interesante otra interpretación desde la óptica de la beneficencia laica, tal vez teñida de cierta excentricidad en la emulación o re-creación de los modelos clásicos de evergetismo o beneficio desinteresado ofrecido por grandes personajes públicos a una determinada ciudad ${ }^{38}$. En claves contemporáneas, también podemos atribuir al gesto del reparto de panes una intención propagandística de los promotores del ferrocarril, que vendría a reforzar la expresión del conjunto del periódico que hemos analizado, aunque el perfil del público objetivo al que iría dirigida -los pobres- no se corresponda con el del público con capacidad coercitiva para oponerse a tal obra pública. El texto del anuncio contiene elementos bastante significativos de comunión con las ideas liberales de beneficencia laica que se habían abierto camino frente a la caridad religiosa. El reparto de panes se efectuaría en la panadería de Francisco Rosado, o sea, un obrador de pan, desligándose así su distribución de la puerta de conventos, casas de obispos y palacios nobiliarios; y ciñéndola a los conceptos de producción y fabricación. También es significativo el motivo del reparto, sin conexión con ningún evento religioso -la concesión del ferrocarril-, es decir, el comienzo de una gran obra pública. Y aunque la supervisión de la distribución de los panes quede a cargo de dos órdenes religiosas, ello se circunscribe estrechamente a lo dictado en el Real Decreto de 29 de julio de 1837 que hemos comentado más arriba.

\section{Conclusiones}

Creemos que el caso de los Loring-Heredia-Larios es singular para toda España a mediados del siglo XIX, ya que, si bien existieron otras familias burguesas en los ámbitos locales de distintas regiones dedicadas al comercio y los negocios, no alcanzaron sus niveles de capitalización ni de diversificación. Este grupo empresarial más bien podría compararse con grupos familiares de inversión franceses como los Péreire, como hemos comentado. Asimismo, también es probable que por esta razón su mentalidad mantuviese más semejanzas con las corrientes europeas de pensamiento que con la del resto del entorno andaluz y español, destacando por ello su originalidad de actuación respecto a la sociedad general, producto y reflejo de sus negocios.

La reutilización y la re-creación de la Antigüedad clásica funcionaron como elementos de prestigio para la burguesía malagueña de mediados del siglo XIX, mediante su apropiación en la Edad Contemporánea con las formas de los símbolos originales del mundo antiguo; tal como fueron reutilizados por la monarquía y la aristocracia durante el Antiguo Régimen. Esta burguesía no sólo reutilizó símbolos icónicos, sino formas de interacción con el pueblo llano que, aunque quedaban yuxtapuestas ambiguamente con las formas correspondientes a la tradicional caridad 
cristiana, podrían ser interpretadas en claves de evergetismo, por las connotaciones de laicismo que conllevan.

En torno a la cuestión de los posibles sustratos ideológicos o de las mentalidades que sostuvieron la idea decimonónica del "progreso" en Málaga, con los escasos datos fehacientes y menos pruebas concluyentes que podemos ofrecer en este trabajo, sólo podríamos conjeturar que en las logias andaluzas de la Orden del Gran Arquitecto del Universo anteriores a su legalización en España se hubiere transmitido la esencia de las ideas del saint-simonismo. O si el aparente saint-simonismo que se infiere de la forma de negocios integrados de ámbito regional de los Loring-Heredia-Larios, con numerosos puntos en común a la de los hermanos Péreire franceses, debería ser puesto en conjunción con la filosofía de Saint-Simon o sus discípulos de forma directa, o analizado a través de la absorción de ésta a través de la clandestina masonería.

En pleno siglo XIX, aquel momento de grandes cambios en el mundo, cuando las estructuras seculares del Antiguo Régimen se desmoronaban, nada podía impedir creer que no fueran a surgir nuevas religiones que sustituyesen o suplantasen a las antiguas. Verdaderamente surgieron o se acrecentaron auténticas manifestaciones espirituales basadas en nuevas fórmulas. Un buen ejemplo de ello es el paso que dio el saint-simonismo desde una óptica de finalidad o causalidad ética hacia el bien común y una filosofía de racionalización del "progreso" imparable, hacia una religión concretada en aspectos mistéricos. También las acusaciones de la Iglesia católica hacia la masonería de pretender erigirse en nueva religión -infundadas o no-, son sinónimo de que cupiera imaginar la desintegración de los viejos credos y su sustitución por otros incipientes; lo cuál debiera estar materializándose en ciertos parámetros del pensamiento colectivo.

Si por motivos que desconocemos los propios protagonistas de esta historia, o sus descendientes, eliminaron documentación comprometedora de sus propios archivos familiares o de otros archivos con entidad en la ciudad, es más que probable que pudiesen aparecer nuevos documentos en otros repertorios que quizás quedaron olvidados, como los que se han mencionado de las minas de Belmez u otros lugares.

\section{Referencias bibliográficas}

ALLO MANERO, $\mathrm{M}^{\mathrm{a}}$ Adelaida (2003) "La mitología en las exequias reales de la Casa de Austria", en De Arte, 2, pp. 145-164.

ÁLVAREZ LÁZARO, Pedro (1999) "La Institución Libre de Enseñanza en la tradición del pensamiento masónico europeo", conferencia extraída de UREÑA, E. M.; ÁLVAREZ LÁZARO, P. (eds.) (1999) La actualidad del krausismo en su contexto europeo, Editorial Parteluz-Fundación Duques de Soria-UPCo, Madrid, $25 \mathrm{pp}$., disponible en http://www.colectivoginer.com/htm/lazaro2.pdf [última consulta 23/03/2015]. 
BALLESTEROS GARCÍA, Rosa Ma (2000), "El Folletín (1872-1873): Imagen social de las burguesas malagueñas en la coyuntura de la Primera República", en Revista Jábega, 85, Centro de Ediciones de la Diputación de Málaga, pp. 42-54.

BEJARANO ROBLES, Francisco (1947), Historia del Consulado y de la Junta de Comercio de Málaga, 1875-1859, C.S.I.C., Madrid, 442 pp.

BELTRÁN FORTES, José; GARCÍA GARCÍA, Miguel Ángel; RODRÍGUEZ OLIVA, Pedro (2006) Los sarcófagos romanos de Andalucía, Vol. 1, fasc. 3, Tabvlarivm, Murcia, pp. 42-45.

BRODER, Albert (1998) Histoire économique de l'Espagne contemporaine, Economica, París, 357 pp., p. 66.

CAMPOS ROJAS, M ${ }^{a}$ Victoria (1987) "Jorge Loring Oyarzábal: Primer Marqués de Casa-Loring (1822-1900)", Jábega 58, Centro de Ediciones de la Diputación de Málaga, pp. 32, 34 y ss.

CHECA GODOY, Antonio (2011) Historia de la prensa andaluza, Ediciones Alfar, S. A. Sevilla, pp. 113-114.

CHEVALIER, Jean; GHEERBRANT, Alain (1985) Diccionario de los símbolos, Herder, Barcelona, pp. 347-350.

COLE, G. D. H. (1957) Historia del pensamiento socialista I. Los Precursores 17891850, Fondo de Cultura Económica, México, pp. 13 y ss.

CUÉLLAR VILLAR, Domingo; SÁNCHEZ PICÓN, Andrés (dirs.) (2008), 150 años de ferrocarril en Andalucía: un balance [Tomo I], Junta de Andalucía-Consejería de Obras Públicas y Transportes- y Fundación de los Ferrocarriles Españoles; Servicio de Publicaciones. Dirección general de Planificación de la Consejería de Obras Públicas y Transportes, Madrid, pp. 103-109.

DAZA SÁNCHEZ, Antonio (2005) "Causalidad en minas y masonería de Belmez a Málaga en el siglo XIX, reconocimiento a Leopoldo Alcántara y Jorge Loring", en Boletín de la Real Academia de Ciencias, Bellas Letras y Nobles Artes de Córdoba, 129, p. 268, disponible en http://helvia.uco.es/xmlui/handle/10396/7360 [última consulta 29/01/2015].

DE MATEO AVILÉS (1985) Paternalismo burgués y beneficencia religiosa en la Málaga de la segunda mitad del siglo XIX, Servicio de Publicaciones de la Diputación Provincial de Málaga, Málaga, pp. 11-15 y 57-66.

DE MATEO AVILÉS, (1986) Masonería, protestantismo, librepensamiento y otras heterodoxias en la Málaga del siglo XIX, Diputación Provincial de Málaga, pp. 77-150.

DE MATEO AVILÉS, Elías (1986) Masonería, protestantismo, librepensamiento y otras heterodoxias en la Málaga del siglo XIX, Diputación Provincial de Málaga, pp. 21-27.

DE SOLA, Amelia (1979) “El Avisador Malagueño (1843-1893). Apuntes para su estudio", en revista Baetica. Estudios de Arte, Geografía e Historia, 2-II, Universidad de Málaga, pp. 295-314, disponible en http://dialnet.unirioja.es/servlet/articulo? codigo $=3822217$ [última consulta 23/03/2015].

FARGETTE, Guy (2001) Émile et Isaac Pereire- L'esprit d'entreprise au XIXe siècle, L'Harmattan, Paris, 322 pp. 
FERRER BENIMELI, José A. (1980) Masonería española contemporánea, Vol. 1 (1800-1860), Siglo XXI, Madrid, pp. 23-29.

FERRER BENIMELI, José Antonio (2010) "Métodos y experiencias en el estudio de la historia de la masonería española", en Revista de Estudios Históricos de la Masonería Latinoamericana y Caribeña (REHMLAC), Vol. 1, $\mathrm{n}^{\mathrm{o}} 2$, Diciembre 2009-Abril 2010, pp. 44-61, disponible en http://dialnet.unirioja.es/servlet/articulo? codigo $=3097230$ [última consulta 03/02/2015].

FERRERAS, Juan Ignacio (1979) Catálogo de novelas y novelistas españoles del siglo XIX, Ediciones Cátedra, S.A., p. 160.

GARCÍA ESPAÑA, José Juan (1975), en la revista Historia. Instituciones. Documentos, Publicaciones de la Universidad de Sevilla, pp. 45-188, disponible en http://institucional.us.es/revistas/historia/02/02\%20garcia\%20espana.pdf [última consulta 28/01/2015].

GONZÁLEZ JURADO, Deborah (2014) "El papel del ferrocarril en la distribución de prensa y publicidad entre 1865 y 1941. El caso de la Compañía de los Ferrocarriles de Madrid a Zaragoza y Alicante, y algunos antecedentes", en Revista TST (Transportes, Servicios y Comunicaciones), $\mathrm{n}^{\circ}$ 27, pp. 76-78.

HALL, James (1987) Diccionario de temas y símbolos artísticos, Alianza Editorial, pp. 91-92.

JIMENEZ QUINTERO, José Antonio (1979) "Mentalidad empresarial y acumulación de capital en la casa Larios en Málaga", en Cuadernos de Ciencias Económicas y Empresariales, $\mathrm{n}^{\circ} 4$, 1979, pp. 215-246, disponible en http://dialnet.unirioja. es/servlet/articulo?codigo=2290324 [última consulta 29/01/2015].

LACOMBA, Juan Antonio (1974), “El ferrocarril Málaga-Córdoba (1859-1879)”, en Jábega, 7, Centro de Ediciones de la Diputación de Málaga, pp. 53 y ss.

LEIDEN (et al.) (2004) Brill's, Encyclopaedia of the Ancient World New Pauly, Brill Leiden-Boston, pp. 154-155.

LÓPEZ CASTELLANO, Fernando (2004) Las raices históricas del tercer sector, documento de trabajo núm. 1/2004, Universidad de Granada, 185 pp.

LOWENTHAL, David (1998) El pasado es un país extraño, Akal, Madrid, p. 29.

MARCHANT RIVERA, Alicia (2004) "Moradas de la "escritura última": fuentes documentales para la historia del cementerio inglés de Málaga", en Revista de Historiografia $\mathrm{n}^{\circ}$ 1, I (1/2004), Instituto de Historiografía "Julio Caro Baroja", Universidad Carlos III, Getafe, $165 \mathrm{pp}$.

MARTIN, Marc (1992), Trois siècles de publicité en France, Editions Odile Jacob, Paris, pp. 75-78.

MARTÍNEZ MAZA, Clelia (2009) "Los orígenes de la historiografía sobre paganismo tardoantiguo", en Mainake, XXXI/2009, pp. 197-207, disponible en http://dialnet. unirioja.es/servlet/articulo? codigo=3283510 [última consulta 23/03/2015].

MARTÍNEZ MAZA, Clelia (2010) "Democracia ateniense vs. revolución americana", en Potestas. Revista del Grupo Europeo de Investigación Histórica, $\mathrm{n}^{\mathrm{o}} 3$, pp. 215-226, disponible en http://dialnet.unirioja.es/servlet/articulo? codigo $=3304119$ [última consulta 06/02/2015]. 
MORALES MUÑOZ, Manuel (1983) "El Banco de Málaga: Factor descapitalizador de la economía malagueña", Jábega, 41, Centro de Ediciones de la Diputación de Málaga, pp. 53 y ss.

MORALES MUÑOZ, Manuel (1999) "El papel de las élites en la industrialización andaluza", en Baetica. Estudios de Arte, Geografia e Historia, 21, Universidad de Málaga, pp. 431-449.

NADAL, Jordi (1975) El fracaso de la revolución industrial en España, 1814-1913, Ariel S.A., Barcelona.

OLÍAS RUIZ, Emilio; BARRADO Bautista, Andrés (2006) "Antecedentes anglosajones del ferrocarril Málaga-Córdoba (1860-1865). Apuntes sobre la vida de Jorge (George) Loring James", en IV Congreso de Historia ferroviaria, Málaga, 12 pp. disponible en http://www.docutren.com/HistoriaFerroviaria/Malaga2006/pdf/I04. pdf [última consulta 31/01/2015].

OLIVENCIA RUIZ, Manuel (1986) "Suspensión de pagos y quiebra en el Código de Comercio", pp. 348 y ss., en Centenario del Código de Comercio, volumen 1, Ministerio de Justicia, Madrid, 1986, 1097 pp., disponible en https://books. google.es [última consulta 28/01/2015].

ORDÓÑEZ VERGARA, Javier (1993) "La ciudad como escenario para la muerte en el siglo XIX: Las honras fúnebres de M. A. Heredia en Málaga", en Baetica. Estudios de Arte, Geografia e Historia 15, 1993, pp. 21-29.

OSSORIO Y BERNARD, Manuel (2004) Ensayo de un catálogo de periodistas españoles del siglo XIX. Edición facsímil de la publicada en 1904, Ayuntamiento de Madrid, Hemeroteca Municipal, p. 144.

PERDICES DE BLAS, Luis; SÁNCHEZ HORMIGO, Alfonso (2007) 500 Años de economía a través de los libros españoles y portugueses, Fundación Ramón Areces, Zaragoza, p. 101.

PÉREZ LÓPEZ, Isabel (2005) "El siglo XIX. La Historia Antigua en dos historias de Málaga", en WULFF ALONSO, Fernando; CHENOLL ALFARO, Rafael; PÉREZ LÓPEZ, Isabel (coords.) La tradición clásica en Málaga (siglos XVI-XXI) III Congreso de Historia Antigua de Málaga, pp. 75-79.

PINTO MOLINA, María (1987), La masonería en Málaga y provincia (Último tercio del siglo XIX), Universidad de Granada, pp. 21-25.

RAMOS FRENDO, Eva María (2000) Amalia Heredia Livermore, Marquesa de Casa-Loring, Universidad de Málaga, 299 pp.

RAMOS PALOMO, $\mathrm{M}^{\mathrm{a}}$ Dolores (1985) "Estructura social en Málaga (I): El vértice del poder, 1900-1920", en Baetica. Estudios de Arte, Geografía e Historia, no 8, Universidad de Málaga, pp. 515-534, disponible en http://dialnet.unirioja.es/ servlet/articulo?codigo $=95115$ [última consulta 27/01/2015].

REVILLA, Federico (1990) Diccionario de iconografia, Cátedra, Madrid, pp. 102-103.

RODRÍGUEZ DE BERLANGA, Manuel (1853) Estudios sobre los dos bronces encontrados en Málaga a fines de octubre de 1851, Imprenta del Avisador Malagueño, Málaga, 52 pp., se puede consultar íntegramente en línea en http://www. 
bibliotecavirtualdeandalucia.es/catalogo/consulta/registro.cmd?id=1013455 [última consulta 29/01/2015].

RODRÍGUEZ DE BERLANGA, Manuel (1995 facsímil, $1^{\text {a }}$ edición 1903) Catálogo del Museo Loringiano, Servicio de Publicaciones e Intercambio Científico de la UMA, Málaga, 193 pp. más anexo de fotograbados.

RODRÍGUEZ OLIVA, Pedro (1995) "Comentarios sobre el Museo Arqueológico de los Loring en la malagueña Finca de La Concepción y sobre el Dr. Manuel Rodríguez de Berlanga, autor de su catálogo", pp. 9-28, en RODRÍGUEZ DE BERLANGA, Manuel (1995 facsímil, $1^{\text {a }}$ edición 1903) Catálogo del Museo Loringiano, Servicio de Publicaciones e Intercambio Científico de la UMA, Málaga.

RODRÍGUEZ OLIVA, Pedro (2001) "Noticias historiográficas sobre el descubrimiento y los primeros estudios en torno a las tablas de bronce con las leyes municipales de Málaga y Salpensa (1851-1864)", en Mainake, XXIII, Servicio de Publicaciones de la Diputación de Málaga, disponible en http://www.cedma.es/ catalogo/mainake.php?ref=13013 [última consulta 27/01/2015].

RODRÍGUEZ OLIVA, Pedro (2006) "Sobre el autor del proyecto del templete dórico del Mueseo Loringiano: Arquitectos alemanes en "La Concepción"”, en Mainake XXVIII, 2006, pp. 531-562, disponible en http://es.calameo.com/ books/004009353ab44f6b62ee1 [última consulta 23/03/2015].

SÁNCHEZ HORMIGO, Alfonso (2004) "La recepción del pensamiento saint-simoniano en España", Boletim de Ciências Económicas, Faculdade de Direito, Coimbra, pp. 245-270, disponible en http://hdl.handle.net/10316.2/24898 [última consulta 29/01/2015].

TEDDE DE LORCA, Pedro (1978) "El proceso de formación de la Compañía de los Ferrocarriles Andaluces (1874-1880)", en Revista Hacienda Pública Española: review of public economics, Vol. 55, Madrid, pp. 367 y ss.

UGARTE VIAL, Jorge (2010) "Democracia y derecho natural en Estados Unidos. El Pensamiento de los padres fundadores", en Estudios Públicos, 119 (invierno 2010), pp. 151-187, disponible en http://www.cepchile.cl/dms/archivo_4681_2837/ rev119 ugarte.pdf [última consulta 06/02/2015].

VILLAS TINOCO, Siro (2002) "Sobre López de Peñalver, la hidráulica y el Guadalmedina", en Baetica. Estudios de Arte, Geografia e Historia, n 24, Universidad de Málaga, pp. 461-478, Facultad de Filosofía y Letras, Universidad de Málaga, disponible en http://dialnet.unirioja.es/servlet/articulo?codigo=295305 [última consulta 27/01/2015].

VOVELLE, Michel (1985) Ideologías y mentalidades, Duplex S.A., Barcelona. VV. AA. (2008) Manuel Rodríguez de Berlanga. Liber amicovum (1825-1909), Real Academia de Bellas Artes de San Telmo/ Ayuntamiento de Alhaurín el Grande, Málaga, p. 60, disponible en www.academia.edu [última consulta 03/02/2015].

WULFF ALONSO, Fernando (2002) "Historias europeas: Rodríguez de Berlanga, Th. Mommsen y las leyes municipales de Malaga y Salpensa", en Revista Péndulo, Colegio de Ingenieros Técnicos Industriales de Málaga, número XIV/Diciembre 2002, pp. 114 y ss. 
WULFF ALONSO, Fernando (2003) Las Esencias Patrias, Crítica S.L., Barcelona, p. 90.

WULFF ALONSO, Fernando (2005) "La Historia Antigua en la historiografía de Málaga (XVI-XVIII)", en WULFF ALONSO, Fernando; CHENOLL ALFARO, Rafael; PÉREZ LÓPEZ, Isabel (coords.) (2005) La tradición clásica en Málaga (siglos XVI-XXI) III Congreso de Historia Antigua de Málaga, pp. 46 y ss.

\section{Notas}

1 Este trabajo es un adelanto de la tesis doctoral de la autora, Comunicación, Publicidad y Modernidad. El caso del eje ferroviario Madrid-Córdoba-Málaga (1848-1936), dirigida por Bernardo Díaz Nosty y financiada por el programa de becas FPU (Formación del Profesorado Universitario), del Ministerio de Educación, Cultura y Deportes español. Agradecemos las orientaciones bibliográficas y las correcciones aportadas para este artículo a los profesores Jean-Marc Buigues, Pedro Rodríguez Oliva, Fernando Wulff Alonso, Juan Antonio Sánchez López, Antonio Escudero Gutiérrez, Andrés Sánchez Picón y José Antonio Ferrer Benimeli; y la búsqueda de datos al responsable del archivo histórico del Registro Mercantil de Málaga, Curro Moreno. Las hipótesis expresadas, la redacción final y su resultado son responsabilidad exclusiva de la autora.

This work is a preview of the doctoral thesis of the author, Communication, Advertising and Modernity. The case of the railway axis Madrid-Córdoba-Málaga (1848-1936), directed by professor Bernardo Diaz Nosty and funded scholarship program FPU (University Teacher Training), Spanish Ministry of Education, Culture and Sports. We would like to thanks the bibliographic guidance and the corrections made by the professors Jean-Marc Buigues, Pedro Rodríguez Oliva, Fernando Wulff Alonso, Juan Antonio Sánchez López, Antonio Escudero Gutiérrez, Andrés Sánchez Picón y José Antonio Ferrer Benimeli; and to Curro Moreno, responsible of the archive of Malaga Mercantile Register, for his help with the data search. The hypotheses expressed, the final wording and its result are the responsibility of the author.

2 Jorge Loring fue sobrino político del Marqués de Salamanca, suegro de Francisco Silvela y de José Figueroa Torres, hermano del Conde Romanones; por citar algunos ejemplos de filiación por linaje de la saga constituida por Loring-Heredia. Sobre las genealogías y los negocios de las familias Loring-Heredia-Larios ver: $\mathrm{M}^{\mathrm{a}}$ Victoria Campos Rojas (1987) "Jorge Loring Oyarzábal: Primer Marqués de Casa-Loring (1822-1900)", Jábega 58, Centro de Ediciones de la Diputación de Málaga, pp. 32, 34 y ss; José Antonio Jiménez Quintero (1979) "Mentalidad empresarial y acumulación de capital en la casa Larios en Málaga", en Cuadernos de Ciencias Económicas y Empresariales, nº 4, 1979, pp. 215-246, disponible en http://dialnet.unirioja.es/servlet/articulo?codigo=2290324 [última consulta 29/01/2015]; $M^{\mathrm{a}}$ Dolores Ramos Palomo (1985) "Estructura social en Málaga (I): El vértice del poder, 1900-1920", en Baetica. Estudios de Arte, Geografia e Historia, nº 8, Universidad de Málaga, pp. 519 y ss., disponible en http://dialnet.unirioja.es/servlet/articulo?codigo=95115 [última consulta 27/01/2015]; Emilio Olías Ruiz y Andrés Barrado Bautista (2006) "Antecedentes anglosajones del ferrocarril Málaga-Córdoba (1860-1865). Apuntes sobre la vida de Jorge (George) Loring James", en IV Congreso de Historia ferroviaria, Málaga, $12 \mathrm{pp}$. disponible en http://www.docutren.com/ HistoriaFerroviaria/Malaga2006/pdf/I04.pdf [última consulta 31/01/2015]; Javier Ordóñez Vergara (1993) "La ciudad como escenario para la muerte en el siglo XIX: Las honras fúnebres de M. A. Heredia en Málaga", en Baetica. Estudios de Arte, Geografia e Historia, $n^{\circ} 15,1993$, pp. 21 y ss.; Eva María Ramos Frendo (2000) Amalia Heredia Livermore, Marquesa de Casa-Loring, Universidad de Málaga, 299 pp.

3 Ticknor, Irving, Motley y Prescott, entre los más insignes.

4 Fernando Wulff Alonso (2003), op. cit., pp. 65-76. 
5 Fernando Wulff Alonso (2005), op. cit., pp. 30-64.

6 Fernando Wulff Alonso (2003), op. cit., pp. 97-100.

7 El Correo de Andalucía, no 2 (01/11/1851) en Archivo Municipal de Málaga, disponible en http:// archivomunicipal.malaga.eu/es/biblioteca-hemeroteca/\#.VMjhu8b4E-8, aunque el siguiente número que encontramos a continuación será de 1858; y en el Archivo Díaz de Escovar, dicha colección comienza a partir de 1860, disponible en http://www.archivodiazescovar.com/prensa2.php?selpren$\mathrm{sa}=$ CORREO+ANDALUCIA\&fechaprensa $=\&$ selvarios $=$ [últimas consultas 27/01/2015].

8 Para el nombramiento de Rodríguez de Berlanga como académico correspondiente de la Real Academia de la Historia ver: Pedro Rodríguez Oliva (1995) "Comentarios sobre el Museo Arqueológico de los Loring en la malagueña Finca de La Concepción y sobre el Dr. Manuel Rodríguez de Berlanga, autor de su catálogo", p. 16, en Manuel Rodríguez de Berlanga (1995 facsímil, 1ª edición 1903) Catálogo del Museo Loringiano, Servicio de Publicaciones e Intercambio Científico de la UMA, Málaga; y VV. AA. (2008) Manuel Rodríguez de Berlanga. Liber amicovum (1825-1909), Real Academia de Bellas Artes de San Telmo/ Ayuntamiento de Alhaurín el Grande, Málaga, p. 60, disponible en www. academia.edu [última consulta 03/02/2015].

$9 \mathrm{M}^{\mathrm{a}}$ Victoria Campos Rojas (1987) op. cit., pp. 32, 34 y ss.

10 Existe otra pequeña colección de El Correo de Andalucía en la Hemeroteca Nacional de Madrid, aunque sólo comprende los años de 1859 a 1862, en GARCÍA GALINDO, Juan Antonio (1978) "Publicaciones periódicas malagueñas en la Hemeroteca Municipal de Madrid", en Baetica. Estudios de Arte, Geografia e Historia, 1, Universidad de Málaga, p. 408, disponible en http://dialnet.unirioja. es/servlet/articulo?codigo=3822129 [última consulta 28/01/2015].

11 Hemos consultado en los fondos del archivo histórico del Registro Mercantil de Málaga, pero no queda ningún rastro de las fundaciones de El Avisador Malagueño ni del Correo de Andalucía. La base de datos de este registro, que está conectada a las del resto de España, sólo ofrece un resultado de El Correo de Andalucía, S.A., pero se trata de otro periódico diferente con el mismo nombre de cabecera, fundado en Sevilla a principios del siglo XX. Tampoco existen registros a nombre de la imprenta del periódico ni de sus titulares, los Franquelo. A este respecto, sólo indicar que el Registro Mercantil sufrió dos quemas graves en 1931 y 1936, en las que se perdieron gran parte de sus fondos documentales. El $\mathrm{n}^{\circ} 1$ del periódico, donde podrían venir datos sobre la procedencia del capital para su fundación, no se conserva. El n 2 tampoco hay ninguna información a este respecto. Hemos revisado lo que queda de las colecciones de El Correo... y de El Avisador ..., pero como están incompletas $\mathrm{y}$ con saltos de varios años, los números que existen no coinciden con los aniversarios de fundación de $E l$ Correo..., en los que tal vez pudiera rememorarse el inicio de la publicación.

12 Esta vía aún existe con el mismo nombre en el centro histórico de la ciudad.

13 Sobre los entresijos del descubrimiento y su promoción en el mundo académico, consultar el estudio preliminar de Pedro Rodríguez Oliva (1995) op. cit., p. 15 y ss.

14 El Avisador Malagueño, en línea en el Archivo Díaz de Escovar de la Fundación Unicaja, desde 1844 hasta 1893, disponible en http://www.archivodiazescovar.com/prensa2.php?selprensa=EL+AVISADOR+MALAGUE\%D1O\&fechaprensa=\&selvarios= [última consulta 27 de enero de 2015]. De este diario también se conserva otra colección el Archivo Municipal de Málaga. Este periódico pionero por sus contenidos y forma de tratar la información, ha sido escasamente estudiado hasta el momento, ver: Amelia De Sola (1979) "El Avisador Malagueño (1843-1893). Apuntes para su estudio", en Baetica. Estudios de Arte, Geografia e Historia, 2-II, Universidad de Málaga, pp. 295-314, disponible en http://dialnet.unirioja.es/servlet/articulo?codigo=3822217 [última consulta 27/01/2015].

15 Hemos hallado semejanzas en forma y fondo con El Avisador..., en la revista The Art-Journal Advertiser, publicada en Londres, especializada en publicidad, y con una forma de trabajo de plataforma de negocios con corresponsales en diferentes países. En la Biblioteca Nacional de España, en Madrid, 
puede consultarse una colección de The Art-Journal Advertiser, cuyo primer número es el 131, de mayo de 1849 (BNAlcalá, ZA/657). Otra colección se conserva en la Library of Congress, disponible en http://catalog.loc.gov [última consulta 23/01/2015].

16 Sobre los orígenes del Consulado de Comercio de Málaga, creado por Carlos III en 1785 mediante Real cédula, siguiendo el modelo recogido en la Novísima Recopilación, y el proyecto para la formación de nuevas ordenanzas en 1825, consúltense la transcripción de las copias impresas de 1785 ofrecida por José Juan García España (1975), en la revista Historia. Instituciones. Documentos, Publicaciones de la Universidad de Sevilla, pp. 45-188, disponible en http://institucional.us.es/ revistas/historia/02/02\%20garcia\%20espana.pdf; y Manuel Olivencia Ruiz (1986) "Suspensión de pagos y quiebra en el Código de Comercio", pp. 348 y ss., en Centenario del Código de Comercio, volumen 1, Ministerio de Justicia, Madrid, 1986, 1097 pp., disponible en https://books.google.es [últimas consultas 28/01/2015].

17 Sobre las Actas de la Junta de Comercio de Málaga es destacable el trabajo realizado por Francisco Bejarano Robles (1947) Historia del Consulado y de la Junta de Comercio de Málaga, 1875-1859, C.S.I.C., Madrid; pero en él no existe ningún capítulo, ni referencia o mención sobre prensa y otras cuestiones relacionadas con imprentas o empresas informativas de la época. El autor enfocó su trabajo en cuestiones de mayor trascendencia de la municipalidad, como las obras de reforma del puerto de Málaga, e incluso confecciona un capítulo dedicado al ferrocarril, pero obvió las cuestiones acerca de su difusión pública a través de la prensa o la impresión de folletos o panfletos. Los originales manuscritos de estas Actas, sí contienen numerosas menciones a las actividades de comunicación pública de la Junta, incluso con expresa mención a los títulos de los periódicos y las inserciones que en ellos realizaba. Tal vez, Bejarano obvió el análisis de estas informaciones de las Actas, porque en el momento en el que realizó su estudio, este tipo de estudios históricos sobre prensa, no estaba aún desarrollado en nuestro país, y debía tenerse por un tema menor al que no se le concedía importancia por la historiografía del momento.

18 Sobre la documentación de la Cámara de Comercio de Málaga, damos aquí testimonio de la eliminación total de su archivo documental en los años de la crisis económica (aprox. 2009, 2010 ó 2011). El archivo histórico fue tirado literalmente a la basura por la dirección gerente de aquellos años, por falta de presupuesto para su conservación, sin intentar previamente enviarlo, cederlo o donarlo a otra institución. Sólo se han conservado los libros de Actas, de los que extraemos esta información: Actas de la Junta de Comercio (1844-1854), Cámara de Comercio de Málaga.

19 En las Actas de la Junta de Comercio de Málaga de 3, 14 y 19 de enero de 1843, se ordenaba la publicación de los anuncios oficiales de la Junta en El Despertador Malagueño, diario liberal más antiguo del que existen dos pequeñas colecciones incompletas en los archivos Díaz de Escovar y Municipal. Los números extremos conservados de El Despertador ... en ambos archivos van desde el 11 de diciembre de 1831 al 10 de diciembre de 1843. Aunque no tenemos certeza de la fecha exacta del cierre de su edición, El Despertador ... debió desaparecer suplantado por la pujanza del nuevo y vanguardista Avisador...

20 En el acta de la Junta ordinaria de 13 de julio de 1844 viene referida explícitamente una empresa municipal del Ferrocarril de María Cristina, "invitando al Comercio á que se interese en ella".

21 En Francia los Péreire invirtieron grandes sumas de capital en Le Globe, periódico abiertamente al saint-simonismo y en una agrupación de varios periódicos importantes para la gestión común de su publicidad, que dio lugar a la creación de la Société Générale de Annonces (SGA), la cual se desamortizó a partir de la crisis de 1848. Ver: Marc Martin (1992), Trois siècles de publicité en France, Editions Odile Jacob, Paris, pp. 75-78.

22 Agradecemos de corazón a Albert Broder el regalo de este libro y sus enseñanzas, en París, octubre de 2014.

23 En el estudio de Elías De Mateo Avilés (1986) Masonería, protestantismo, librepensamiento y otras heterodoxias en la Málaga del siglo XIX, Diputación Provincial de Málaga, pp. 77-150, no se indaga 
en la identificación de los miembros de las logias que presenta. Y el estudio de la profesora María Pinto Molina (1987) La masonería en Málaga y provincia (Último tercio del siglo XIX), Universidad de Granada, pp. 21-25, comienza en la etapa de la Restauración, momento de gran auge y esplendor de la Institución, debido a un período de gobierno liberal que legalizó la masonería en 1879, contribuyendo a la reorganización de ésta en las siguientes décadas.

24 DAZA SÁNCHEZ, Antonio (2005), op. cit, p. 266.

25 PINTO MOLINA, María (1987), op. cit, pp. 89-91.

26 PINTO MOLINA, María (1987), íbid., pp. 21-22.

27 DAZA SÁNCHEZ, Antonio (2005), op. cit., p. 266.

28 CAMPOS ROJAS, $\mathrm{M}^{\text {a }}$ Victoria (1987), op. cit., pp. 37-38.

29 La corona de laurel simboliza la dignidad, el poder, la realeza y el acceso a un rango y fuerzas superiores. Su situación en el vértice de la cabeza significa el nexo entre la realidad humana y el más allá. Su forma circular es sinónimo de perfección y participación en la naturaleza celeste. Se otorga como recompensa de una prueba y promesa de una vida inmortal, señalando la naturaleza del acto heroico cumplido y del premio atribuido. El hombre coronado es un individuo en peculiar comunicación con el orden superior, que capta las fuerzas supraterrenas y las utiliza para lograr la hazaña acometida. En las antiguas Grecia y Roma, la corona de laurel era portada por el dios Apolo, las musas Calíope y Clío y los vencedores de los juegos píticos de Delfos en honor a Apolo. También la llevaban los emperadores romanos y gobernadores provinciales. Para la simbología de la corona de laurel, ver: Jean Chevalier y Alain Gheerbrant (1985) Diccionario de los símbolos, Herder, Barcelona, pp. 347-350, 1107 pp.; James Hall (1987) Diccionario de temas y símbolos artísticos, Alianza Editorial, pp. 91-92, 328 pp.; y Federico Revilla (1990) Diccionario de iconografía, Cátedra, Madrid, pp. 102-103, 404 pp. Para las pervivencias de la mitología y la simbología de la Antigüedad clásica, también ver: Ma Adelaida Allo Manero (2003) "La mitología en las exequias reales de la Casa de Austria”, en De Arte, 2, pp. 145-164.

30 Esta pequeña ilustración, contenida en el recuadro inferior izquierdo, es muy simbólica, pues nos enseña cómo el ferrocarril es capaz de abarcar y contener las formas de transporte anteriores, como eran los coches de caballos. Según la información de la web del Museo de Carruajes de Sevilla, este tipo de coche de caballos de cuatro ruedas era muy común, al ser utilizado como coche de alquiler o de punto. Se trata de un coche de pescante elevado con asiento para dos pasajeros con capota plegable. La forma de su caja puede ser cuadrada o redonda, y era muy usado para pasear por la ciudad en los días soleados. En este coche se podían enganchar un caballo o dos. El coche que representa nuestro ejemplo es de capota redonda. En internet: http://www.galeon.com/juliodominguez/museo. htm [última consulta el 01/01/2015].

31 Otras desavenencias surgieron acerca del trazado definitivo de esta vía férrea, y en el intervalo entre el Real Decreto de 14 de septiembre de 1852, que autorizaba la construcción, y el comienzo del proceso de obras, José de Salamanca, propuso un trazado distinto que abarataba los costes de construcción y el tiempo de ejecución, lo que ocasionó una enconada disputa entre notables. Para más detalles acerca de la construcción del ferrocarril Málaga-Córdoba ver: Domingo Cuéllar Villar y Andrés Sánchez Picón (dirs.) (2008), op. cit., pp. 104 y ss.

32 AHF, Perfil Longitudinal Córdoba-Málaga, 1906.

33 El apartado dedicado a Ramón Franquelo del Catálogo de novelas y novelistas españoles del siglo XIX de Juan Ignacio Ferreras (1979), op. cit., p. 160, contiene un error, que consiste en presentar A Ramón Franquelo como director de El Avisador Malagueño, cuando en realidad lo era, como estamos viendo, de El Correo de Andalucía. Según este catálogo, Ramón Franquelo escribió en 1845 un libro en defensa de la Compañía de Jesús, y hay constancia de otras catorce obras de este autor, y cita: Cuentos, mentiras y exageraciones andaluzas (1848) Madrid; Risa y llanto. Colección de leyendas 
históricas y fantásticas (1850) Imprenta de Gil Montes, Málaga; El corazón de un bandido. Leyenda tomada del drama del mismo título (1852), Madrid; Treinta días después. Segunda parte de "El corazón de un bandido" (1853), Madrid.

34 FERRERAS, Juan Ignacio (1979), op. cit., p. 222.

35 El Correo de Andalucía n 2580 (15/03/1860), Imprenta de Ramón Franquelo, Málaga,p. 3. Respecto al lugar en el que se entregarían los 4.000 panes, comentaremos que actualmente existen dos calles en Málaga con la referencia al gremio prácticamente desaparecido en nuestros días de artesanos del Esparto. Una, Calle Esparteros propiamente dicha, cerca de la iglesia Catedral, a la cuál creemos que se refiere nuestro anuncio; y otra, Calle Hoyo de Esparteros, frente a los puentes que cruzan el río Guadalmedina, dentro del perímetro de la muralla de la ciudad antigua.

36 Actas del Consejo de Administración de la Compañía del Ferrocarril de Madrid a Zaragoza y Alicante (1857-1941) Archivo Histórico Ferroviario en Delicias, Madrid (AHF).

37 Respecto a este enfoque, consultar: Elías De Mateo Avilés (1985) Paternalismo burgués y beneficencia religiosa en la Málaga de la segunda mitad del siglo XIX, Servicio de Publicaciones de la Diputación Provincial de Málaga, Málaga, pp. 11-15 y 57-66; y Rosa Mª Ballesteros García (2000), "El Folletín (1872-1873): Imagen social de las burguesas malagueñas en la coyuntura de la Primera República”, en Revista Jábega, 85, Centro de Ediciones de la Diputación de Málaga, pp. 42-54.

$38 \mathrm{El}$ evergetismo fue un fenómeno central en la ética de reciprocidad de la civilización grecorromana, formando parte de su etimología y su concepto socio-antropológico del intercambio de regalos. En la Antigüedad la evergesía fue un elemento esencial de las relaciones sociales y de la reputación, siendo un elemento decisivo en el reconocimiento de una elevada posición social. Los individuos ricos actuaban como benefactores y debían estar dispuestos a realizar obras pías, siendo al mismo tiempo ésta una de las razones por los que el sistema jerárquico permaneció estable por muchos siglos. Desde antes del siglo $\mathrm{V}$ a. C, evergeta fue un título honorífico otorgado por las comunidades griegas a personas que les rendían servicios particularmente excepcionales. En un principio, los trabajos de ciudadanos individuales por la poli, aún se regulaban mediante liturgias y el título de euergetai era otorgado a los no atenienses, pero más tarde, durante el siglo III a. C. abundaron los euergetai homenajeados en sus propias polis. Los gobernantes helenísticos, a menudo tomaron el epíteto de evergetes y utilizaron la evergesía como instrumento o programa en sus transacciones entre polis. Tanto en Grecia como en Roma los evergetas proveían de alimentos, edificios, escuelas, organizaban juegos, etc., y a cambio podían ser homenajeados con inscripciones, estatuas, festivales, procesiones, etc. Para más información sobre este tema, ver: Leiden (et al.) (2004) Brill's, Encyclopaedia of the Ancient World New Pauly, Brill Leiden-Boston, pp. 154-155. 